\title{
Serum lactic acid dehydrogenase isozyme determination in myocardial infarction
}

\author{
Satya Paul Handa* \\ M.B., B.S. \\ Hartford Hospital, Hartford, Connecticut
}

\section{Introduction}

The principle of electrophoresis is known to be of great use in today's medicine and an expanding literature on this subject supports this view. Various methods for the electrophoretic separation of charged molecules have been developed in the past 15 years. Immunological and physicochemical studies have further increased knowledge of these electrophoretic fractions.

On this principle, Vesell \& Bearn (1957) and Sayre \& Hill (1957) demonstrated that lactic acid dehydrogenase (LDH) exists in multiple electrophoretically distinct forms in human serum. These physically separable molecular forms, having similar enzymatic activities, are known as isozymes (Markert \& Moller, 1959). Various techniques have been employed and there is ample evidence that the LDH in human tissues consists of five isozymes and their activity can be studied in serum (Wieme, 1959 ; Hess \& Walter, 1961 ; Wroblewski, Ross \& Gregory, 1960; Hill, 1961). In addition it has been shown that certain isozymes originatt predominantly from certain tissues (Wroblewski et al., 1960 ; Wieme \& Van Maercke, 1961 ; Vesell, 1961 ; Wroblewski \& Gregory, 1961 ; Nisselbaum \& Bodansky, 1961). Lactic acid dehydrogenase isozyme $1\left(\mathrm{LDH}_{1}\right)$ has been found to arise specifically from cardiac muscle. The tissue specificity of $\mathrm{LDH}$ isozymes is as follows:

$\begin{aligned} & \mathbf{L D H}_{1} \\ & \mathbf{L D H}_{2}\end{aligned}$
$\mathbf{L D H}_{3}-\begin{aligned} & \text { Cardiac muscle } \\ & \text { Erythrocytes } \\ & \text { Kidney }\end{aligned}$
$\left.\begin{array}{l}\mathbf{L D H}_{4} \\ \mathbf{L D H}_{5}\end{array}\right\}$ Lung, pancreas
Liver, skin and skeletal muscles

The purpose of this study was to evaluate the usefulness of the qualitative and quantitative determinations of LDH isozymes in patients with myocardial infarction and other clinical states simulating coronary heart disease.

\footnotetext{
*Present address: Chief Resident in Internal Medicine, at Washington Hospital Centre, Washington, D.C., U.S.A.
}

\section{Materials and methods Group $I$}

This group was composed of thirty-two healthy persons who ranged in age from 40 to 60 years.

\section{Group II (Myocardial infarction)}

Consisted of twenty-six patients, twenty males and six females with an average age of 54 (range 27-78). With the exception of one patient who died 4 days after the onset of myocardial infarction, all patients had an uncomplicated clinical course. The electrocardiogram at the time of admission to the hospital and sequential tracings thereafter showed evidence of acute myocardial infarction, i.e. elevation of the ST segment, inversion of $\mathrm{T}$-waves and the development of Q-waves. Similarly routine enzyme studies of SGOT and total LDH were suggestive of myocardial damage. Of these twenty-six patients, fifteen had posterior myocardial infarction, and in the remaining eleven the electrocardiograms indicated anterior myocardial damage. None of these patients had evidence of right heart failure but were all orthopnoeic at the time of admission. The estimation of LDH isozymes was performed almost daily in each patient for an average period of 12 days and in all $145 \mathrm{LDH}$ isozyme determinations were carried out in this group.

\section{Group III (Miscellaneous)}

This group included two patients with angina pectoris, four with coronary insufficiency, one with myocardial infarction and arrhythmia and one with myocardial infarction followed by severe fatal shock. Four patients with non-specific chest pain in association with other systemic diseases were also studied.

The determination of SGOT, SGPT and LDH were performed as described by Bowers (1963). The results are expressed in International Units ( $1 \mu \mathrm{mole} / \mathrm{min}$ at $30^{\circ}$ ) per $\mathrm{ml}$ of serum, and the normal ranges in milliunits are taken as 3-20 $\mathrm{mU} / \mathrm{ml}$ for SGOT, 3-15 $\mathrm{mU} / \mathrm{ml}$ for SGPT and $100-220 \mathrm{mU} / \mathrm{ml}$ for $\mathrm{LDH}$.

Serum lactic dehydrogenase electrophoretic fractionation was carried out by cellulose acetate 


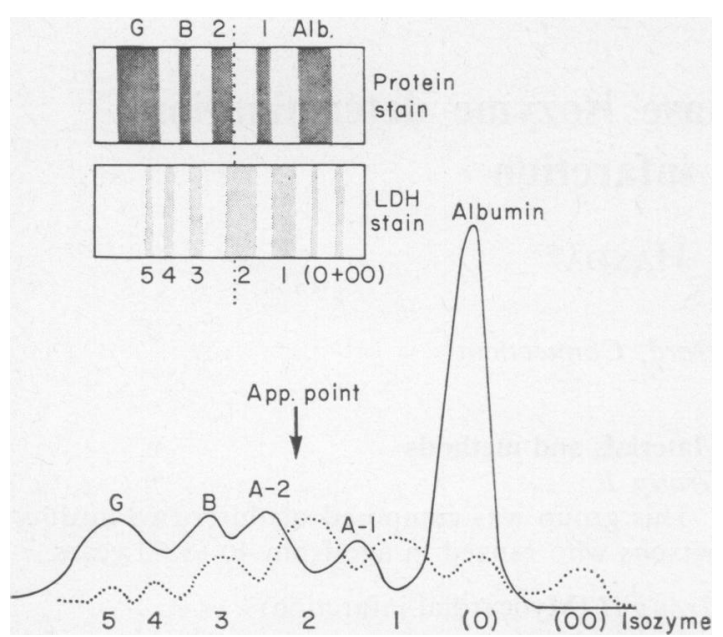

FIG. 1. A diagrammatic representation of protein and LDH electrophoretic patterns.

electrophoresis (Bartlett, 1963) and histochemical staining by a modification of the method described by Barnett (1964). Densitometric quantitation was performed utilizing the 'Spinco' analytral (Beckman Instrument Co.). LDH isozyme values were calculated as a percentage of the total LDH. The location of isozyme in the electrophoretic pattern corresponds to the migration of fractions of serum protein as shown in Fig. 1.

Venous blood was collected in dry glassware and allowed to clot at room temperature, care being taken to avoid haemolysis. SGOT, SGPT and $\mathrm{LDH}$ enzyme activities were estimated on the same day. The LDH isozyme determination was done either the same day or within the next 5 days with serum held at $4^{\circ}$.

\section{Results}

The mean serum LDH value in thirty-two healthy controls in the present study was 185 with a standard deviation (SD) \pm 9 . In this group, all serum specimens showed at the most four isozymes. The mean value of each individual isozyme is given in Table 1 . In all control subjects but two the $\mathrm{LDH}_{2}$ was greater than $\mathrm{LDH}_{1}$. The mean $\mathrm{LDH}_{1}: \mathrm{LDH}_{2}$ ratio was 0.70 (SD \pm 0.02 ).

All patients with myocardial infarction showed an elevation in $\mathrm{LDH}_{1}$ with a shift of the $\mathrm{LDH}_{1}: \mathrm{LDH}_{2}$ ratio to more than unity. The mean $\mathrm{LDH}_{1}: \mathrm{LDH}_{2}$ ratio in these patients was 1.48 (SD \pm 0.05$)$. Thirteen patients in this group had an elevation of SGPT more than 25 units on two occasions during their stay in the hospital. Of these thirteen patients, four showed the appearance of $\mathrm{LDH}_{5}$ in their isozyme pattern. Liver function tests were normal. The elevations in values of $\mathrm{LDH}_{1}$ and $\mathrm{LDH}_{1}: \mathrm{LDH}_{2}$ ratio above unity lasted for a period more than 12 days unlike those of SGOT and total serum LDH determinations (see Fig. 2). No specific alteration in isozyme values as a result of medications such as anticoagulants and sedatives was noted.

In Table 2 it can be seen that in patients with angina pectoris there was no rise in $\mathbf{L D H}_{1}$ and no shift in $\mathrm{LDH}_{1}: \mathrm{LDH}_{2}$ ratio to more than unity. Three of the four patients with coronary insufficiency selected for this report had alterations in their isozyme patterns, suggestive of myocardia damage. Two had these changes even in the absence of a simultaneous rise in serum enzyme studies. The rise in $\mathrm{LDH}_{1}$ greater than that in $\mathrm{LDH}_{2}$ in patient No. 6 was evidence of fresh myocardial damage over an old antero-septal and lateral infarction, and 5 days later a typical pattern of recent infarction appeared on the ECG. Serial isozyme determinations consistent with myocardial damage was present in only this patient, out of four with coronary insufficiency. Similar results were evident in patient No. 7 in whom underlying myocardial infarction was concealed by arrhythmias.

The patients of most interest were those with hepatitis and myocardial infarction complicated

TABLE 1

Lactic acid dehydrogenase isozyme activity in serum

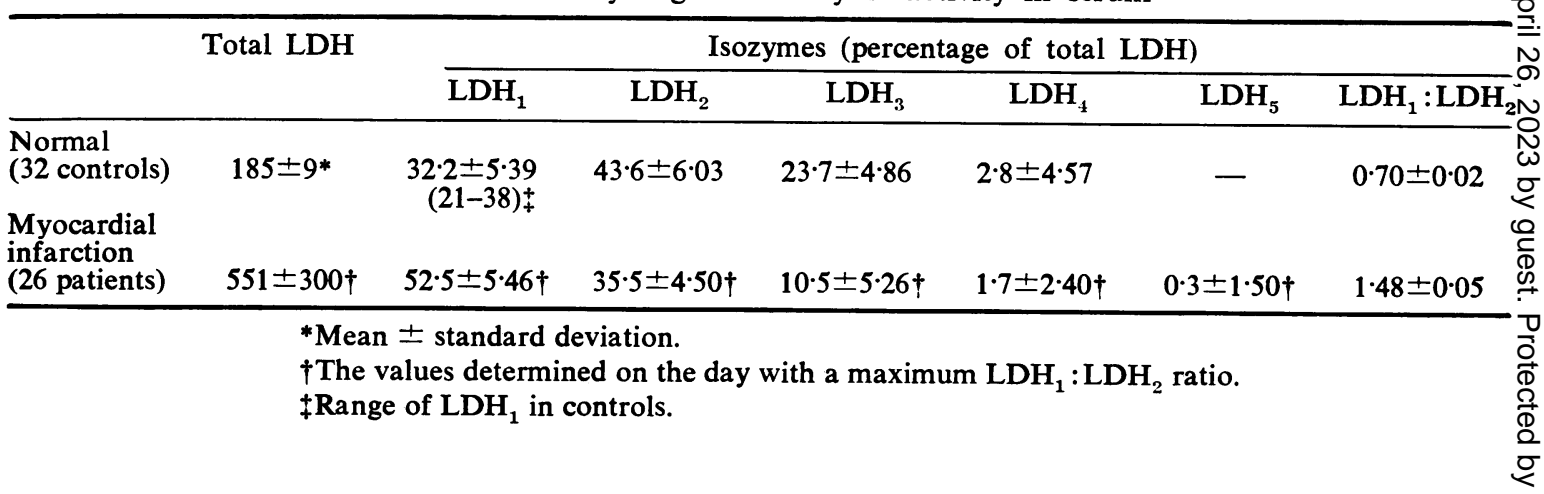



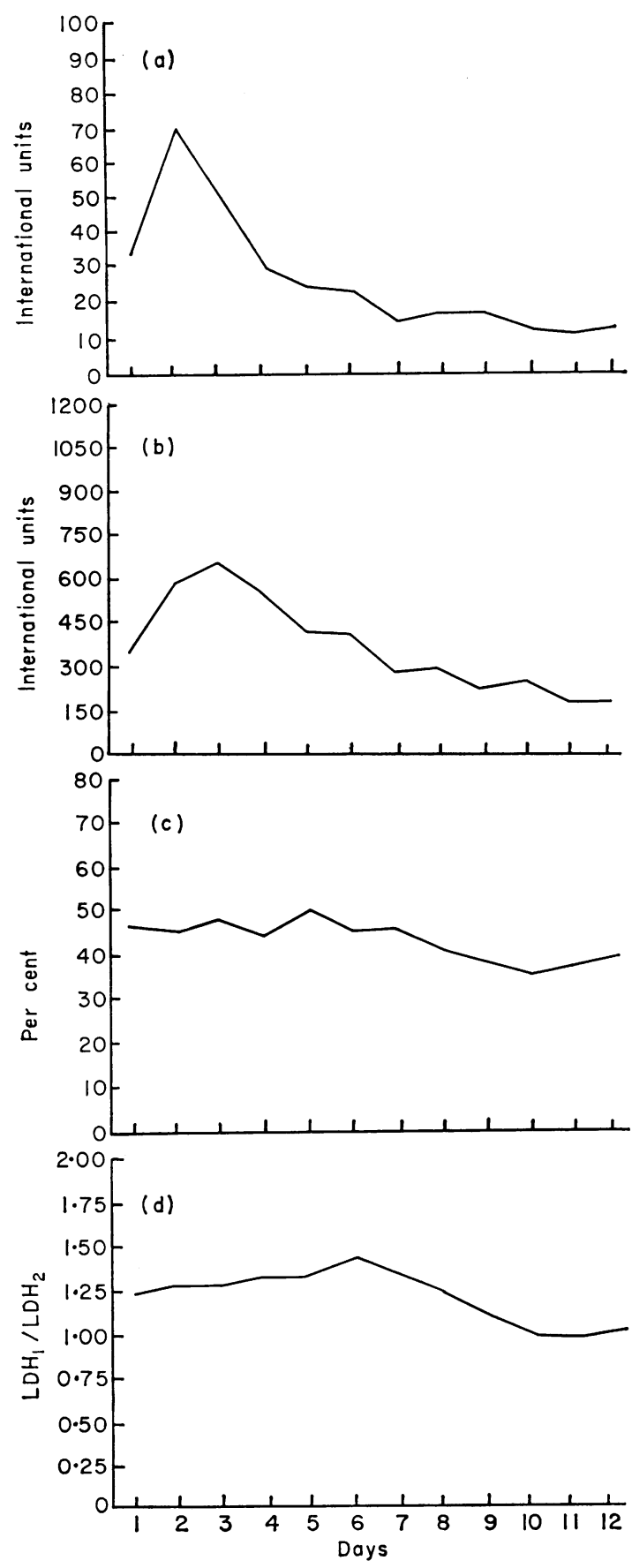

FIG. 2. Serum enzyme levels following acute myocardial infarction (mean value of twenty-six patients). (a) Serum glutamic oxaloacetic transaminase, (b) serum lactic acid dehydrogenase, (c) serum lactic acid dehydrogenase isozyme 1 , (per cent of total LDH) ( $\alpha$ ) ratio. by shock. The rise in $\mathrm{LDH}_{5}$ unequivocally supported the evidence of liver damage. However, in the latter, despite a high level of total LDH, the lack of $\mathrm{LDH}_{1}$ elevation was striking.

Non-specific chest pain in association with diabetes mellitus did not exhibit any change in the isozyme pattern. This patient (No. 10) was admitted with a history of hypertension and unusually severe abdominal pain and precordial discomfort. The ECG showed left ventricular hypertrophy and myocardial ischaemia; however, the enzyme studies and isozyme determinations were apparently within normal limits. She was investigated and found to have cholelithiasis with cholecystitis and pancreatitis.

In spite of markedly elevated serum LDH, the isozyme distribution in the patient with bronchogenic carcinoma with metastases in the liver did not reveal diagnostic abnormalities. The ECG was normal and the absence of a rise in $\mathbf{L D H}_{1}$ excluded the possibility of underlying myocardial damage.

\section{Discussion}

The use of LDH fractionation in clinical medicine has been known for the last 10 years. The methods usually employed for their determination are complex and expensive. The technique followed in this study has, however, been shown to be simple and useful (Barnett, 1964; Bowers \& Bartlett, 1964). Despite the great difficulties encountered in staining LDH isozymes after their separation on cellulose acetate, minor modifications of Barnett's technique enabled them to be identified and measured.

In the present study, the LDH isozyme patterns recorded in the controls indicated that mean concentrations of $\mathrm{LDH}_{1}$ specific for cardiac muscle were comparable with those reported by others who used different techniques (Vesell \& Bearn, 1957; Weime, 1959; Cohen, Djordjerich \& Ormiste, 1964). Any value above its upper normal range of 38 should be considered abnormal. Cohen et al (1964), in their excellent study, presented the diagnostic significance of the $\mathrm{LDH}_{1}: \mathrm{LDH}_{2}$ ratio in patients with myocardial infarction. Similar results in our study indicate that the $\mathrm{LDH}_{1}: \mathrm{LDH}_{2}$ ratio exceeds unity in patients after myocardial infarction.

The use of $\mathrm{LDH}$ fractionation as a routine laboratory investigation in ECG-proven patients with myocardial infarction is of more diagnostic help than determination of SGOT and LDH; however, the widely used SGOT determination remains a valuable test provided it is interpreted in a proper clinical setting. In contrast to that of serum enzymes, $\mathrm{LDH}_{1}$ isozyme measurement 
TABLE 2

Miscellaneous group

\begin{tabular}{|c|c|c|c|c|c|c|c|c|c|c|}
\hline \multirow{2}{*}{$\begin{array}{c}\text { Patient } \\
\text { No. }\end{array}$} & \multirow[b]{2}{*}{ SGOT } & \multirow[b]{2}{*}{ SGPT } & \multicolumn{6}{|c|}{ Isozyme } & \multicolumn{2}{|l|}{$\underline{\mathrm{LDH}_{1}}$} \\
\hline & & & $\overline{\mathrm{LDH}}$ & $\mathrm{LDH}_{1}$ & $\mathrm{LDH}_{2}$ & $\mathrm{LDH}_{3}$ & $\mathrm{LDH}_{4}$ & $\mathrm{LDH}_{5}$ & $\overline{\mathrm{LDH}_{2}}$ & Comments \\
\hline$\frac{1}{2}$ & $\begin{array}{l}10 \\
15\end{array}$ & $\begin{array}{l}4.0 \\
4.7\end{array}$ & $\begin{array}{l}179 \\
137\end{array}$ & $\begin{array}{l}28 \\
27\end{array}$ & $\begin{array}{l}45 \\
41\end{array}$ & $\begin{array}{l}27 \\
19\end{array}$ & $\begin{array}{r}0 \\
10\end{array}$ & $\begin{array}{l}0 \\
0\end{array}$ & $\begin{array}{l}0.62 \\
0.65\end{array}$ & \multirow{10}{*}{ 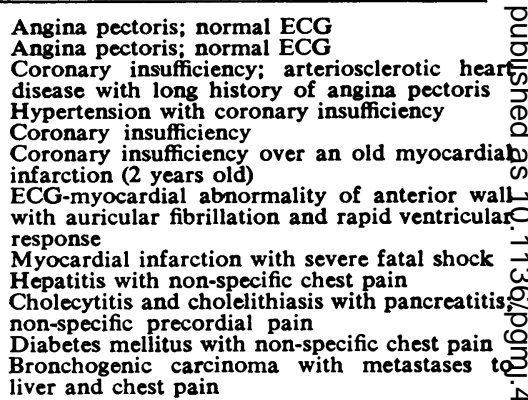 } \\
\hline 3 & 29 & 6.0 & 252 & 50 & 38 & 12 & 0 & 0 & 1.34 & \\
\hline $\begin{array}{l}4 \\
5\end{array}$ & $\begin{array}{l}19 \\
13\end{array}$ & $\begin{array}{r}9.0 \\
10.0\end{array}$ & $\begin{array}{l}130 \\
170\end{array}$ & $\begin{array}{l}29 \\
41\end{array}$ & $\begin{array}{l}42 \\
36\end{array}$ & $\begin{array}{l}29 \\
23\end{array}$ & $\begin{array}{l}0 \\
0\end{array}$ & $\begin{array}{l}0 \\
0\end{array}$ & $\begin{array}{l}0.67 \\
1.14\end{array}$ & \\
\hline 6 & 19 & 4.5 & 134 & 45 & 28 & 17 & 10 & 0 & 1.60 & \\
\hline 7 & 7.5 & 14.0 & 717 & 48 & 34 & 14 & 5 & 0 & 1.41 & \\
\hline 8 & - & - & 4286 & 19 & 24 & 12 & 16 & 30 & - & \\
\hline 9 & 61 & 425 & 1314 & 4 & 30 & 17 & 15 & 34 & - & \\
\hline 10 & 16 & 6.5 & 196 & 28 & 34 & 28 & 10 & - & - & \\
\hline 11 & 12 & 8 & 164 & 27 & 45 & 18 & 10 & - & - & \\
\hline 12 & - & - & 2114 & 25 & 33 & 26 & 12 & 4 & - & \\
\hline
\end{tabular}

serves as a specific and reliable index of myocardial damage and is particularly useful in patients where underlying myocardial damage is concealed by arrhythmias or drug effects or where other systemic diseases may contribute to the rise of SGOT and total LDH.

It was of interest to observe that a rise in SGOT, $\mathrm{LDH}, \mathrm{LDH}$ isozyme 1 and $\mathrm{LDH}_{1}: \mathrm{LDH}_{2}$ ratio occurred simultaneously in the first $24 \mathrm{hr}$ after the onset of myocardial infarction, but the values of the former two enzymes began to decline earlier than the reversal of $\mathrm{LDH}_{1}: \mathrm{LDH}_{2}$ ratio. Patients who are not investigated in the first few days after an attack may show no rise in SGOT and in such circumstances, total $\mathrm{LDH}$ and $\mathrm{LDH}_{1}: \mathrm{LDH}_{2}$ ratio determinations are useful.

Patients with coronary insufficiency and with angina pectoris do not usually show alterations in $\mathrm{LDH}$ isozyme pattern in the absence of concurrent rises in SGOT and LDH ; but evidence of $\mathrm{LDH}_{1}: \mathrm{LDH}_{2}$ ratios greater than unity in patients Nos. 3, 5 and 6 (Table 2) suggests that isozyme determination is a sensitive index of myocardial damage. However, because of the uncertainty of the final diagnosis in patients with angina pectoris and coronary insufficiency, it is clear that the clinical usefulness of LDH isozyme measurements is difficult to assess. Cohen et al. (1964) postulate that an occasional rise in $\mathrm{LDH}_{1}: \mathrm{LDH}_{2}$ ratio to more than unity during the clinical course of coronary insufficiency may represent an alteration in the permeability of cardiac muscle, and such serial determinations are indicative of myocardial necrosis. $\mathrm{LDH}_{1}$ elevation has also been noted with different types of haemolytic anaemia and renal infarction and these need to be excluded.

The normal isozyme distribution in patient No. 12 confirms a similar finding noted by Bowers \& Bartlett (1964) and Cohen et al. (1966) in patients with carcinoma and metastases. The elevation in $\mathrm{LDH}_{4}$ and $\mathrm{LDH}_{5}$ in shock and in the postresuscitation period after cardiac arrest indicates damage in skin, skeletal muscles and liver. In Table 2 the marked increase in serum LDH of $\vec{z}$ patient No. 8 was primarily due to an abnormality detected in $\mathrm{LDH}_{5}$.

\section{Summary}

Determination of the concentration of the serung lactic acid dehydrogenase isozymes in patients with moycardial infarction, coronary insufficiency and other clinical states simulating coronary artery disease, was carried out by cellulose acetate electrophoresis and histochemical staining by a modification of the method described by Barnett (1964).

The mean peak activities for $\mathrm{LDH}_{1}$ (specific for cardiac muscle) among control subjects and patients with myocardial infarction were 32.2 $(\mathrm{SD} \pm 5 \cdot 39)$ and $52.5(\mathrm{SD} \pm 5 \cdot 46)$ respectively. The abnormal value of $\mathrm{LDH}_{1}$ was observed for an average period of 12 days after the onset of clinical myocardial infarction. The most diagnostic finding was an $\mathrm{LDH}_{1}: \mathrm{LDH}_{2}$ ratio which shifted towards a figure greater than unity in patients with myocardial necrosis. The mean $\mathrm{LDH}_{1}: \mathrm{LDH}_{2}$ ratio among controls was 0.70 (SD $\pm 0 \cdot 62)$.

The results of the present study support the view that LDH isozyme determination is a helpful indication of specific tissue injury in patients with myocardial infarction, but its routine use in doubtful cases of coronary insufficiency and angina pectoris is difficult to evaluate. The enzyme studies of SGOT and total LDH remain a useful guide for the confirmation of myocardial infarction, provided these are interpreted on the basis of clinical findings. 
The study of LDH isozyme fractionation also identified characteristic patterns in various diseases with non-specific chest pain.

\section{Acknowledgment}

A grateful acknowledgment is made to $\mathrm{Dr} \mathbf{G}$. N. Bowers, Jr., Director, Biochemistry Section, Pathology Department, Hartford Hospital, Hartford, Connecticut, for his help in this study.

\section{References}

BARNETT, H. (1964) The staining of lactic dehydrogenase isozymes after electrophoretic separation on cellulose acetate. J. clin. Path. 17, 567.

BARTLETT, R.C. (1963) Rapid cellulose acetate electrophoresis. I. Serum proteins. Clin. Chem. 9, 317.

BOWERS, G.N., JR (1963) Standard methods. Clin. Chem. 4, 163.

BOWERS, G.N., JR \& BARTLETT, R.C. (1964) Rapid cellulose acetate electrophoresis. III. Separation of lactic dehydrogenase isoenzymes. Presented at the Department of Pathology, University of Rochester, N.Y.

CoHEN, L., DJoRdjevich, J. \& JACoBson, S. (1966) The contribution of isozymes of serum lactic dehydrogenase (LDH) to the diagnosis of specific organ injury. Med. Clin. N. Amer. 50, 193.

CoHEN, L., DJoRdjevich, I. \& ORMiste, V. (1964) Serum lactic dehydrogenase isozyme patterns in cardiovascular and other diseases with particular reference to acute myocardial infarction. J. Lab. clin. Med. 64, 355.
Hess, B. \& Walter, S.I. (1961) Chromatographic differentiation of lactate dehydrogenase of human tissue and serum. Ann. N.Y. Acad. Sci. 94, 890.

HILL, B.R. (1961) Electrophoretic fractionation of serum lactic dehydrogenase. Cancer Res. 21, 271.

MARKERT, C.L. \& MOLLER, F. (1959) Multiple forms of enzymes: tissue, ontogenetic, and species specific patterns. Proc. nat. Acad. Sci. (Wash.), 45, 753.

NisSElbaUM, J.S. \& BodanSKY, O. (1961) Reactions of human tissue lactic dehydrogenase with anti-sera to human heart and liver lactic dehydrogenases. J. biol. Chem. 236, 401.

SAYRE, F.W. \& Hill, B.R. (1957) Fractionation of serum lactic dehydrogenase by salt concentration gradient elution and paper electrophoresis. Proc. Soc. exp. Biol. (N.Y.), 96, 695.

VESELL, E.S. \& BEARN, A.G. (1957) Localisation of lactic acid dehydrogenase activity in serum fractions. Proc. Soc. exp. Biol. (N.Y.), 94, 96.

VESELL, E.S. (1961) Significance of the heterogeneity of lactic dehydrogenase activity in human tissues. Ann. N.Y. Acad. Sci. 94, 877.

WiEME, R.J. (1959) Studies on Agar Gel Electrophoresis. Arscia Uitgaven N.V., Brussels.

WIEME, R.J. \& VAN MAERCKE, Y. (1961) The fifth (electrophoretically slowest) serum lactic dehydrogenase as an index of liver injury. Ann. N.Y. Acad. Sci. 94, 898.

WROBLEWSKI, F. \& GREGORY, K.F. (1961) Lactic dehydrogenase isozymes and their distribution in normal tissues and plasma and in disease states. Ann. N.Y. Acad. Sci. 94, 912.

WroblewSKI, F., ROSS, C. \& GREGORY, K.F. (1960) Isoenzymes and myocardial infarction. New Engl. J. Med. 263, 531 . 